\title{
PENGARUH PENERAPAN MODEL PEMBELAJARAN LANGSUNG BERBANTUAN MEDIA FLIPCHART TERHADAP HASIL BELAJAR TEKNIK TUMPANG TINDIH PADA ALAS PANAS SISWA KELAS XI SMK NEGERI 1 BERASTAGI
}

\author{
Flora Hutapea dan Debora Elfrida Ginting*) \\ Surel: florahutapea@gmail.com
}

\begin{abstract}
The research aims to know: 1) To know the results of learning overlap technique on the base of heat by using conventional learning model of students of class XI SMK Negeri I Berastagi. 2) To know the result of learning technique of overlap on the base of heat after using direct instruction model assisted by flipchart media of student of class XI SMK Negeri 1 Berastagi. 3) To know how far the influence of learning result of overlap technique on the base of heat after using direct instruction model assisted by flipchart media in class XI SMK Negeri 1 Berastagi. The population in this study are 97 students of class XI Kriya Tekstil SMK Negeri 1 Berastagi. Sampling technique using purposive sample that is sampling technique with certain considerations. The sample in this research is 64 students consisting of experiment class of 3 students and control class of 32 students, using quasi experiment method (Quasi experiment). The results of this research indicate that the level of trends in the results of learning overlap technique on the heat base of the class XI Kriya Tekstil SMK Negeri 1 Berastagi for experimental class tend to be very high at $75 \%$. And the tendency level of overlap technique learning result for the control class tends to be high but only 46,87\%. To test the data normality using the Liliefors formula at a significant level of 0.05 with $d k=32$, in obtaining the results of learning data overlap technique on the heat base of experimental class is normally distributebecause Lcount $<$ Ltable $(0.051592<0.156)$ and control class with $d k=32$, is normally distributed because Lcount <Ltable $(0,018296<0,156)$. Homogeneity test, obtained Fcount < Ftabel is $0,45<1,83$ so that both research class have the same variance (homogeneous). The result of hypothesis test by using t-test in obtaining tcount of 4,261 and ttable at significant level 0,05 with $d k=62$ equal to 1,671. Thus tcount>ttable (4,261>1,671). Therefore it can be concluded that there is an effect of the application of direct learning model assisted by flipchart media on the results of learning overlap technique on the heat base of students of class XI SMK Negeri 1 Berastagi. Based on the results of the calculation above, it can be seen that the application of direct learning model assisted by flipchart media is well used in SMK Negeri 1 Berastagi, especially in the sewing lesson.
\end{abstract}

Kata Kunci: Model Pembelajaran Langsung berbantuan Media Flipchart, Teknik Tumpang Tindih

\section{PENDAHULUAN}

$\mathrm{P}$ endidikan merupakan faktor utama dalam pembentukan pribadi manusia. pendidikan sangat berperan dalam membentuk baik dan buruknya pribadi manusia menurut ukuran normatif. Menyadari akan hal tersebut, pemerintah sangat serius menangani bidang pendidikan, sebab dengan sistem pendidikan yang

*) Dra. Flora Hutapea, M.Pd: Dosen Jurusan PKK FT UNIMED
Debora Elfrida Ginting: Mahasiswa Jurusan PKK FT UNIMED

PUSDIBANG - KS UNIMED 
baik diharapkan muncul generasi penerus bangsa yang berkualitas dan mampu menyesuaikan diri untuk hidup bermasyarakat.

SMK merupakan salah satu lembaga pendidikan formal yang mengajarkan suatu keahlian pada bidang tertentu. SMK memiliki tujuan untuk melahirkan /menciptakan tamatan yang sudah memiliki suatu keahlian yang dapat/bersaing dalam mencari suatu pekerjaan. Salah satu jurusan yang ada di SMK Negeri 1 berastagi adalah Kriya Tekstil. Salah satu mata pelajaran yang produktif adalah membuat kriya tekstil dengan teknik jahit perca dan dalam pembelajaran ini siswa dituntut untuk dapat mendiskripsikan jenis jahit perca dan dapat membuat jahit perca dengan berbagai pola dan bentuk dalam berbagai fungsi. Jahit perca adalah proses pembuatan suatu produk kerajinan tekstil yang terbuat dari potongan-potongan kain/perca yang digabungkan dengan cara dijahit sesuai dengan rencana.

Agar siswa mampu berprestasi serta mengembangkan potensinya, maka perlu dibekali dengan pengetahuan yang cukup. Dengan memiliki pengetahuan, maka siswa dapat dipastikan mampu mencapai tujuan dari bidang studi tersebut. Agar pengetahuan dapat diterima oleh siswa maka guru harus melakukan atau merancang suatu model dalam pembelajaran.
Model pembelajaran adalah cara mengajar yang digunakan dengan maksud untuk mencapai tujuan yang telah ditetapkan. Salah satu model pembelajaran yang dimaksud adalah model pembelajaran langsung. Trianto (2009) model pembelajaran langsung (direct instruction) merupakan salah satu model pembelajaran yang dirancang khusus untuk mengembangkan belajar siswa tentang pengetahuan prosedural dan pengetahuan deklaratif yang terstruktur dengan baik dan dapat dipelajari selangkah demi selangkah.

Berdasarkan hasil wawancara yang dilakukan dengan Ibu Elita Ngadi selaku guru mata pelajaran teknik jahit perca masih banyak siswa yang belum mencapai kriteria ketuntasan minimal (KKM), dimana hasil belajar siswa kelas XI SMK Negeri 1 Berastagi dalam membuat teknik jahit perca masih kurang maksimal dikarenakan siswa kurang serius mengikuti proses belajar. Karena dalam proses pembelajaran tersebut guru masih menggunakan model pembelajaran konvensional. Dimana pada pembelajaran konvensional suasana kelas cenderung Teacher-Centered sehingga siswa menjadi pasif. Guru kurang menggunakan media pembelajaran, hanya dengan menjelaskan konsepkonsep yang ada pada buku ajar/referensi lain. Sehingga masih banyak siswa yang belum tertarik terhadap mata pelajaran ini, siswa 
merasa bosan dan acuh tak acuh dalam belajar. Hal ini lah yang menyebabkan rendahnya hasil belajar teknik jahit perca. Ini dibuktikan dari nilai tes awal siswa yang masih dibawah KKM yang ditentukan yaitu 75

Berdasarkan wawancara tersebut penulis mengadakan tes awal dikelas XII yang sudah mempelajari teknik jahit perca. Hasil tes tersebut menunjukkan 11 dari 34 siswa mendapat nilai B berkisar 32,35\% yang lulus KKM. Selain itu 23 siswa mendapatkan nilai $C$ berkisar $67,65 \%$ yang tidak lulus KKM. Dari tes awal yang dilakukan dapat dilihat hasil belajar teknik jahit perca masih rendah. Oleh karena itu untuk mengatasi masalah tersebut peneliti menawarkan salah satu model pembelajaran yang dapat menunjang kelancaran proses pembelajaran yaitu dengan menggunakan model pembelajaran langsung berbantuan media flipchart sebagai upaya meningkatkan hasil belajar teknik jahit perca.

Aunurrahman

(2012),

pembelajaran langsung adalah suatu model pembelajaran dimana kegiatannya terfokus pada aktifitasaktifitas akademik, dengan model pembelajaran langsung ini guru dapat memberikan arahan dan kontrol yang ketat terhadap kemajuan belajar siswa. Tujuan model pembelajaran langsung adalah untuk memaksimalkan penggunaan waktu belajar siswa, dan dampak daripada metode ini adalah meningkatnya motivasi belajar siswa, meningkatnya kemampuan siswa serta meningkatnya percaya diri siswa.

Salah satu kelebihan model pembelajaran langsung ini sangat sesuai jika guru menginginkan siswa menguasai informasi atau keterampilan tertentu, karena siswa secara langsung melihat demostrasi yang diberikan oleh guru. Siswa dapat melihat langsung proses atau cara kerja suatu benda yang berkenan dengan bahan pelajaran agar siswa tidak hanya menghafal konsep. Adakalanya guru juga memberi kesempatan kepada siswa untuk bertanya jika ada yang kurang dipahami menyangkut materi yang dijelaskan.

Dalam hal ini juga untuk menunjang pencapaian kompetensi siswa media pembelajaran yang digunakan juga sangat berperan dengan menggunakan media flipchart atau bagan balikan yang dapat menyajikan setiap informasi dan mempermudah siswa untuk lebih berperan serta aktif dalam proses kegiatan belajar mengajar dan pembelajaran menjadi lebih interaktif.

Berdasarkan uraian diatas penulis tertarik untuk mengadakan permasalahan tersebut sebagai topik yang diteliti dengan judul " Pengaruh Penerapan Model Pembelajaran Langsung Berbantuan Media Flipchart Terhadap Hasil Belajar 
Teknik Tumpang Tindih pada Alas Panas Siswa XI Kriya Tekstil SMK Negeri 1 Berastagi".

\section{METODE PENELITIAN}

Desain penelitian adalah suatu cara untuk mencari kebenaran suatu masalah dengan mengumpulkan data yang diperlukan untuk mencapai tujuan yang diinginkan. Desain penelitian yang digunakan dalam penelitian ini adalah Posttest Only Control Design. Sementara metode penelitian yang digunakan adalah metode eksperimen semu (Quasi experiment) yaitu peneliti dapat mengontrol semua variabel luar yang mempengaruhi jalannya eksperimen (Sugiyono, 2011).

\section{Tabel Desain Penelitian}

\begin{tabular}{|l|l|c|}
\hline \multicolumn{1}{|c|}{ Kelas } & Perlakuan & Uji \\
\hline Kontrol & $\begin{array}{l}\text { Pembelajaran } \\
\text { dengan } \\
\text { menggunakan } \\
\text { model }\end{array}$ & Post \\
& Test \\
& pembelajaran & \\
konvensional. & \\
\hline Eksperimen & $\begin{array}{l}\text { Pembelajaran } \\
\text { dengan }\end{array}$ & Post \\
& Test \\
& menggunakan & \\
& model & \\
& pembelajaran & \\
& langsung & \\
& berbantuan & \\
& media & \\
& flipchart. & \\
\hline
\end{tabular}

\section{Keterangan :}

a. Melaksanakan perlakuan mengajar, yaitu melakukan perlakuan mengajar menggunakan model pembelajaran konvensional pada kelas kontrol dan memberikan perlakuan mengajar menggunakan model pembelajaran langsung berbantuan media flipchart pada kelas eksperimen.

b. Mengadakan post test, yaitu mengadakan tes pada kedua kelas, baik kelas kontrol maupun kelas eksperimen setelah kedua kelas diberi perlakuan masing-masing.

Adapun teknik pengambilan sampel ini adalah teknik Purposive Sample yaitu teknik sampling yang digunakan peneliti dengan pertimbangan-pertimbangan tertentu (Sugiyono, 2011). Dalam hal ini yang menjadi pertimbangan penulis adalah:

1. Yang menjadi kelas kontrol adalah kelas XI KT 3 dan kelas eksperimen adalah kelas XI KT 2 dengan alasan bahwa kedua kelas tersebut diajar oleh guru yang sama.

2. Kedua sampel penelitian di atas memiliki nilai rata-rata yang sama

$$
\text { Dalam pelaksanaan }
$$
penelitian, ada beberapa langkahlangkah yang harus dilalui, yaitu sebagai berikut :

1. Tahap Persiapan

Pada tahap ini meliputi persiapan-persiapan sehubungan 
dengan pelaksanaan penelitian, sebagai berikut:

a. Berdiskusi dengan dosen pembimbing terkait masalah penelitian yang akan dibahas.

b. Melakukan observasi ke sekolah tempat tujuan penelitian untuk melihat langsung bagaimana proses pembelajaran di sekolah dan melihat bagaimana peran siswa di dalam kelas saat guru sedang menyampaikan materi, serta mencari masalah yang dihadapi untuk selanjutnya menjadi bahan penelitian.

c. Melakukan wawancara kepada guru bidang studi jahit perca kelas XI Kriya Tekstil untuk mengetahui hasil belajar siswa pada mata pelajaran teknik jahit perca.

d. Menentukan kelas sampel dari populasi yang ada.

e. Menyusun RPP dengan model pembelajaran langsung berbantuan media flipchart.

f. Menyusun posstest.

2. Tahap Pelaksanaan

a. Melakukan

pengajaran kepada kedua kelas yaitu :

1) Pada kelas kontrol adalah mengajarkan materi jahit perca dengan tanpa menggunakan media pembelajaran.

2) Pada kelas eksperimen adalah mengajarkan materi jahit perca dengan

menggunakan media pembelajaran flipchart.

b. Melakukan Posstest

Setelah pembelajaran selesai, peneliti akan melakukan posstest untuk mengetahui kemampuan akhir siswa pada kelas kontrol dan kelas eksperimen.

1. Melakukan pengolahan data posstest.

2. Menarik kesimpulan dan saran.

Instrumen yang digunakan untuk menjaring data hasil belajar teknik jahit perca yaitu melalui pengamatan yang dilakukan oleh lima orang pengamat dimana kelima pengamat (observer) dianggap ahli dalam bidang teknik jahit perca dan layak untuk mengisi lembar penilaian dalam hal kemampuan teknik jahit perca. Kemudian nilai rata-rata dari lima pengamat akan menjadi data dalam penelitian ini. Pengamatan ini berbentuk pengamatan yang sekaligus dilakukan penilaian dari pengamat terhadap objek yang diamati.

Untuk dapat memberikan gambaran terhadap data penelitian yang diperoleh, maka terlebih dahulu dihitung besaran rata-rata skor (mean) dan standart deviasi (SD) sebagai berikut :

1. Mentabulasi skor kelas kontrol.

2. Mentabulasi skor kelas eksperimen. 
3. Menentukan nilai rata-rata masing-masing kelompok (Irianto, 2009) :

$$
M=\frac{\sum x}{N}
$$

Keterangan :

M : (Mean) Harga rata - rata hitung

$\Sigma x \quad$ : Jumlah skor yang dicapai

$\mathrm{N} \quad$ : Banyaknya sampel

4. Untuk menghitung standart deviasi atau simpangan baku digunakan :

$$
S=\sqrt{\frac{\sum x^{2}-\frac{\left(\sum X^{2}\right.}{N}}{N}}
$$

Keterangan :

S : Standart deviasi

$\sum x^{2} \quad$ : Jumlah skor yang dicapai

$\mathrm{N} \quad$ : Banyaknya sampel

5. Untuk menghitung interval kelas digunakan rumus sebagai berikut :

1) $\bar{X}=\frac{\sum x}{N}=\frac{\text { Jumlah skor }}{\text { Banyak siswa }}$

2) Rentang $=$ skor tertinggi skor terendah

3) Panjang kelas (P) = Rentang

4) Interval kelas $K=1+3,3 \log n$

5) Banyak kelas $(\mathrm{K})=\frac{R}{i}$

\section{HASIL PENELITIAN DAN} PEMBAHASAN

Instrumen penelitian diperoleh dari data hasil belajar teknik tumpang tindih pada alas panas dengan menggunakan model pembelajaran langsung berbantuan media flipchart dan hasil belajar teknik tumpang tindih pada alas panas dengan tanpa menggunakan model pembelajaran langsung berbantuan media flipchart.

Berdasarkan data hasil penelitian, dengan 32 sampel diketahui nilai tertinggi 100 dan nilai terendah 90 dengan rata-rata nilai (M) adalah 96,21 dan standart deviasi adalah 2,72 .

Tabel Distribusi Frekuensi hasil belajar teknik tumpang tindih pada alas panas pada kelas eksperimen

\begin{tabular}{|c|c|c|c|}
\hline Kelas & $\begin{array}{c}\text { Interval } \\
\text { Nilai }\end{array}$ & $\begin{array}{c}\text { Frek. } \\
\text { Absolut }\end{array}$ & $\begin{array}{c}\text { Frek. } \\
\text { Relatif } \\
(\%)\end{array}$ \\
\hline 1. & $99-100$ & 14 & 43,75 \\
\hline 2. & $97-98$ & 7 & 21,87 \\
\hline 3. & $95-96$ & 4 & 12,5 \\
\hline 4. & $93-94$ & 5 & 15,63 \\
\hline 5. & $91-92$ & 2 & 6,25 \\
\hline & & 32 & 100 \\
\hline
\end{tabular}

Berdasarkan perhitungan hasil belajar teknik tumpang tindih pada alas panas kelas eksperimen disesuaikan dengan kriteria ketuntasan minimum (KKM) SMK Negeri 1 Berastagi. Nilai ideal tertinggi adalah 100 dan nilai ideal terendah adalah 50 . 


\section{Tabel Tingkat Kecenderungan \\ Data Hasil Belajar Teknik \\ Tumpang Tindih pada Alas \\ Panas Kelas Eksperimen}

\begin{tabular}{|l|l|l|l|}
\hline Keterangan & $\begin{array}{l}\mathbf{f}_{\text {absol }} \\
\text { ut }\end{array}$ & $\mathbf{f}_{\text {relatif }}$ & Kategori \\
\hline $95-100$ & 24 & $75 \%$ & $\begin{array}{l}\text { Sangat } \\
\text { Baik }\end{array}$ \\
\hline $85-94$ & 8 & $25 \%$ & Baik \\
\hline $76-84$ & 0 & $0 \%$ & Cukup \\
\hline$<75$ & 0 & $0 \%$ & Kurang \\
\hline Jumlah & 32 & $100 \%$ & \\
\hline
\end{tabular}

Dari tabel di atas dapat dilihat

bahwa jumlah responden yang termasuk kategori sangat baik dengan jumlah 24 siswa (75\%), kategori baik dengan jumlah 8 siswa (25\%), kategori cukup dan kategori kurang tidak ada terdapat frekuensi. Dengan demikian dapat disimpulkan bahwa hasil belajar menjahit alas panas dengan teknik tumpang tindih dikelas eksperimen tergolong dalam kategori sangat tinggi (75\%).

Hasil perhitungan yang diperolah dari data hasil belajar teknik tumpang tindih pada alas panas kelas eksperimen memperoleh nilai ratarata 96,21 dengan nilai tertinggi 100 dan standart deviasi 2,72 sedangkan pada kelas kontrol memperoleh nilai rata-rata 80 dengan nilai tertinggi 88 dan standar deviasi 5,97.

Berdasarkan hasil uji kecenderungan diketahui hasil belajar teknik tumpang tindih pada alas panas pada kelas eksperimen dikategorikan sangat tinggi. Hal ini dapat dilihat dari 32 responden, bahwa jumlah responden yang termasuk kategori sangat baik dengan jumlah 24 siswa (75\%), kategori baik dengan jumlah 8 siswa (25\%), pada kategori cukup dan kategori kurang tidak ada terdapat frekuensi. Dengan demikian dapat disimpulkan bahwa hasi belajar teknik tumpang tindih pada alas panas di kelas eksperimen tergolong dalam kategori sangat baik (75\%).

Pada kelas kontrol dapat dilihat bahwa jumlah responden yang termasuk dalam kategori baik dengan jumlah 15 siswa $(46,87 \%)$, kategori cukup dengan jumlah 9 siswa $(28,13)$ dan kategori kurang dengan jumlah 8 siswa $(25 \%)$. dengan demikian dapat disimpulkan bahwa hasil belajar teknik tumpang tindih pada alas panas di kelas kontrol tergolong dalam kategori baik $(46,87)$.

Hasil uji hipotesis yang menyatakan bahwa terdapat pengaruh penerapan model pembelajaran langsung berbantuan media flipchart terhadap hasil belajar teknik tumpang tindih pada alas panas siswa kelas XI Kriya Tekstil SMK Negeri 1 Berastagi dengan hasil perhitungan $t_{\text {hitung }}>t_{\text {tabel }}$ atau 4,261 $>1,671$ sehingga dapat dikatakan bahwa terdapat pengaruh penerapan model pembelajaran langsung berbantuan media flipchart terhadap hasil belajar teknik tumpang tindih pada alas panas siswa kelas XI Kriya Tekstil SMK Negeri 1 Berastagi. 
Berdasarkan hasil penelitian, terlihat bahwa hasil belajar kelas eksperimen lebih baik dari pada hasil belajar kelas kontrol. Hal tersebut terlihat dari nilai rata-rata kelas eksperimen dan kelas kontrol. Kelas eksperimen memiliki nilai rata-rata 96,21 dan kelas kontrol memiliki nilai rata-rata 80 .

Adanya pengaruh hasil belajar pada kelas eksperimen dan kelas kontrol disebabkan oleh adanya perlakuan yang dilakukan, yaitu dengan menggunakan model pembelajaran langsung berbantuan media flipchart pada kelas eksperimen.

Berdasarkan hasil pengamatan yang dilakukan penulis ketika pembelajaran dengan menggunakan model pembelajaran langsung berbantuan media flipchart, tampak tingkat partisipasi dan semangat siswa dalam belajar semakin hidup dan berkembang. Mata pelajaran teknik jahit perca merupakan mata pelajaran yang memerlukan kemampuan psikomotorik yang tinggi, jika pada mata pelajaran ini peran guru dalam mengadakan mengajar dan penggunaan media kurang maksimal, maka tingkat partisipasi dan kemauan siswa kurang karena tidak ada dorongan motivasi dari seorang guru.

Hal ini diperkuat dengan hasil

penelitian Novita Sari (2015) "Pengaruh Model Pembelajaran Langsung (Direct Instruction) Berbantuan Media Papan Flanel
Terhadap Hasil Menjahit Belahan di SMK Awal Karya Pembangunan.”. Hasil penelitian menunjukkan bahwa hasil menjahit belahan menggunakan model pembelajaran langsung berbantuan media papan flanel berada pada kategori tinggi dengan persentase $45 \%$, sedangkan hasil menjahit belahan menggunakan model pembelajaran langsung tanpa media sebagian besar berada pada kategori kurang dengan persentase $55 \%$.

\section{SIMPULAN}

Berdasarkan hasil penelitian yang diuraikan, maka dapat disimpulkan sebagai berikut :

1. Hasil belajar teknik tumpang tindih pada alas panas di kelas eksperimen berada pada tingkat kecenderungan kategori sangat baik $(75 \%)$

2. Hasil belajar teknik tumpang tindih pada alas panas di kelas kontrol berada pada tingkat kecenderungan kategori baik $(46,87 \%)$

3. Berdasarkan hasil pengujian hipotesis diketahui bahwa terdapat pengaruh penerapan model pembelajaran langsung berbantuan media flipchart terhadap hasil belajar teknik tumpang tindih pada alas panas siswa kelas XI Kriya Tekstil SMK Negeri 1 Berastagi dengan hasil pengujian hipotesis $t_{\text {hitung }}>t_{\text {tabel }}$ atau 4,261 $>1,671$. 
Untuk perbaikan dan penelitian selanjutnya, ada beberapa saran ynag diberikan antara lain :

1. Bagi guru bidang studi teknik jahit perca agar menciptakan suasana belajar yang menarik dan menyenangkan dengan menggunakan model pembelajaran berbantuan media agar memperoleh hasil belajar teknik jahit perca siswa lebih maksimal.

2. Bagi peneliti lain yang ingin melakukan penelitian sejenis harus mampu menciptakan model pembelajaran berbantuan media yang lebih menarik lagi untuk digunakan dalam penelitian, agar dapat meningkatkan hasil belajar.

3. Diharapkan kepada seluruh siswa untuk lebih aktif dan lebih sering mengulang pembelajaran yang disajikan oleh guru mata pelajaran teknik jahit perca agar hasil belajar dapat terus meningkat menjadi lebih baik

\section{DAFTAR PUSTAKA}

Arikunto, Suharsimi. 2006. Prosedur Penelitian Suatu Pendekatan Praktis.Jakarta: Rineka Cipta

Arsyad, Azhar .2010. Media Pembelajaran. Jakarta : Rajawali Pers
Aunurrahman.2012. Belajar dan Pembelajaran. Bandung: Alfabeta.

Budiono,dkk.2008. Kriya Tekstil untuk SMK jilid 2.Jakarta: Direktorat Pembinaan Sekolah Menengah Kejuruan.

Depdiknas. 2007. Kamus Besar Bahasa Indonesia (Edisi Ketiga). Jakarta: Balai Pustaka Fathurrohman, Muhammad. 2015. Model-model Pembelajaran Inovatif: alternatif desain pembelajaran ysng menyenangkan. Jogjakarta: AR-RUZZ MEDIA

Hamalik, O. 2009. Proses Belajar Mengajar. Jakarta: PT. Bumi Aksara

Hamdani.2011. Strategi Belajar Mengajar. Bandung: $\mathrm{CV}$ PUSTAKA SETIA

Hariyany, Lusia. 2011. Desain aplikasi dari kain perca. Surabaya: Tiara Aksa

Hasibuan (2015), Judul : Peningkatan hasil belajar membuat kerajinan kotak pensil dari perca tekstil dengan menggunakan model pembelajaran langsung (direct instruction) pada siswa kelas $\mathrm{X}$ di SMK Negeri 3 Tebing Tinggi. Perpustakaan Negeri Medan.

Khalilullah.2007. Media Pembelajaran Bahasa Arab. Yogyakarta: Aswaja Pressindo 
Rusman.2013. Belajar dan Pembelajaran berbasis komputer: mengembangkan profesionalisme abad 21. Bandung: Alfabeta

Sadiman, Arief S (dkk).2010. Media Pendidikan: Pengertian, Pengembangan dan Pemanfaatannya. Jakarta: Rajawali Pers.

Sanjaya, H. Wina. 2008 Perencanaandandesainsistemp embelajaran. Jakarta: Kencana

Sari (2015), Judul : Pengaruh model pembelajaran langsung (direct instruction) berbantuan media papan flanel terhadap hasil menjahit belahan di SMK Awal Karya Pembangunan. Perpustakaan Negeri Medan

Shoimin, Aris.2014. 68 Model Pembelajaran Inovatif dalam kurikulum 2013. Yogyakarta: Ar-Ruzz Media

Sudjana .2005.EvaluasiHasilBelajar. Jakarta: Bima Aksara

Susilana, Rudi.2009. Media Pembelajaran: Hakikat Pengembangan, Pemanfaatan dan Penilaian. Bandung: CV WACANA PRIMA.

Sugiyono.2012. Metode Penelitian

Pendidikan: Pendekatan

Kuantitatif, Kualitatif dan

$R \& D$. Bandung: Alfabeta.
Sutikno, Sobry.2013. Belajar dan Pembelajaran "Upaya Kreatif dalam mewujudkan pembelajaran yang berhasil". Lombok: Holistica

Trianto.2009. Mendesain Model Pembelajaran InovatifProgresif. Surabaya: Kencana Prenada Media Group.

Yunita, Eka.2011. Pacthwork \& Quilting untuk Pemula dengan kain perca. Jakarta Selatan: Demedia Pustaka

http://www.dumetschool.com/blog/Te ori-Warna-sebagai-UnsurPenting-Dunia-Desain/ di akses 11 mei 2016

Tim Fakultas Teknik Universitas Negeri Surabaya. Menjahit Lenan rumah tangga. Pdf./ di akses 05 mei 2016

Wiratama,Yudi.blogspot.co.id/2014/0 1/pembelajarankonvensional pembelajaran.html. 